\title{
TRIBOLOGICAL WEAR BEHAVIOUR OF ELECTRICAL CONTACTS MADE FROM AgNi10 COMPOSITE
}

\begin{abstract}
The effect of tribological wear of contacts made from an AgNi10 alloy on microstructure and electrical properties was investigated. The contacts were tested in duty cycles loaded with alternating current of $10 \mathrm{~A}$ intensity. With this value of the current, intensive arcing of contacts occurred. The contacts were tested in the range of 125 to 500 thousand cycles. The contacting surfaces were reported to suffer a high degree of wear, but electrical resistance of the contact system remained stable.

Keywords: wear behaviour, composite, electrical contact, surface degradation
\end{abstract}

\section{Introduction}

Electrical contacts are expected to offer such properties as high electrical conductivity, abrasive wear resistance, reduced formation of electric arc during switching and reduced welding tendency during operation [1-2]. The electrical and electronics industry often uses new materials based on silver as a metal with the highest electrical conductivity. Pure silver has, however, too low mechanical properties and is too expensive to be used in its native form. Therefore the requirements of reliable performance of electrical contacts combined with simultaneous reduction of silver consumption pose to manufacturers of contacts new and tough tasks involving the continuous and sustainable improvement of production technology $[1,3,4]$.

The most suitable material can be selected after the assessment of the requirements and working conditions under which the contacts are expected to operate. The main factors which determine the choice of material for electrical contacts include the type of conducted current (DC - direct current or $\mathrm{AC}$-alternating current ), arc voltage, resistance to tacking and welding in electric arc, the atmosphere and ambient temperature, and switching frequency. Last but not least in the selection of material is the economic aspect [1,2]. The procedure adopted most frequently assumes that there is one alloying element in the composition of the contact material which acts as an electrical conductor, while other alloying elements are responsible for the required high mechanical properties. However, changing one parameter means changing other parameters, too. For example, silver combined with other metals for improved hardness loses its high electrical and thermal conductivity. The decrease in conductivity is most drastic in the case of additives forming with silver solid solutions. Therefore, the option most recommendable is to increase hardness by adding elements characterized by low solubility in silver or use technologies based on composites [4]. The contacts used most commonly in industry are based on metals with high melting points [5] like W-Ag (high resistance to dross formation, low tendency to welding, the ability to permanently carry high-intensity current), W-Cu and silver alloys like Ag-Cu, Ag-Pd, Ag-Ni (the addition of nickel increases the recrystallization temperature of silver and inhibits grain growth increasing thereby the metal hardness), Ag-C, Ag-CdO (cadmium added to silver reduces the risk of contact welding with the resultant quenching of electric arc formed between two contacts). Recently, however, this alloy is increasingly replaced with a non-toxic alloy of $\mathrm{Ag}-\mathrm{SnO}_{2}$ [1]. Contacts whose operation is characterized by a sliding motion are usually made from metal-graphite materials (silver-graphite and copper-graphite systems) traditionally belonging to the oldest family of contact materials $[1,6]$. Rough estimation of the operating life of electrical contacts is very important, remembering that it also depends on the contact surface roughness and purity [7]. The life of contacts is mainly determined by the loss of mass and change in resistance. This article presents the results of tests carried out on contacts made from the AgNi10 composite operating under the conditions of a low voltage AC and relatively high current load. Nickel in this case acts as a reinforcing phase [2,7], and by the lack of solubility in silver (Fig.1) does not significantly alter the electrical conductivity of the alloy [8,9]. It improves the abrasion resistance and reduces the risk of contacts interlocking during operation. The contacts used most frequently are made of silver-nickel materials with nickel content from 10 to $60 \%$ [1]. They are expected to offer a high resistance to wear caused by

\footnotetext{
* AGH UNIVERSITY OF SCIENCE AND TECHNOLOGY, FACULTY OF NON-FERROUS METALS, AL. A. MICKIEWICZA 30, 30-059 KRAKOW, POLAND

** INSTITUTE OF NON-FERROUS METALS, DEPARTMENT OF FUNCTIONAL MATERIALS, 44-100 GLIWICE, POLAND

\# Corresponding author: gboczkal@agh.edu.pl
} 
chipping and oxidation [10]. Silver-nickel electrical contacts are also resistant to oxidation and corrosion, and behave well at elevated temperatures [11,12]. Due to high oxidation resistance, they are used in the overhead circuit breakers, in industrial power relays, and in various switches, stress controls, cameras and instruments, which should have high resistance to wear. Binary silver-nickel alloys are included in the family of pseudo-alloys and are produced by powder metallurgy.

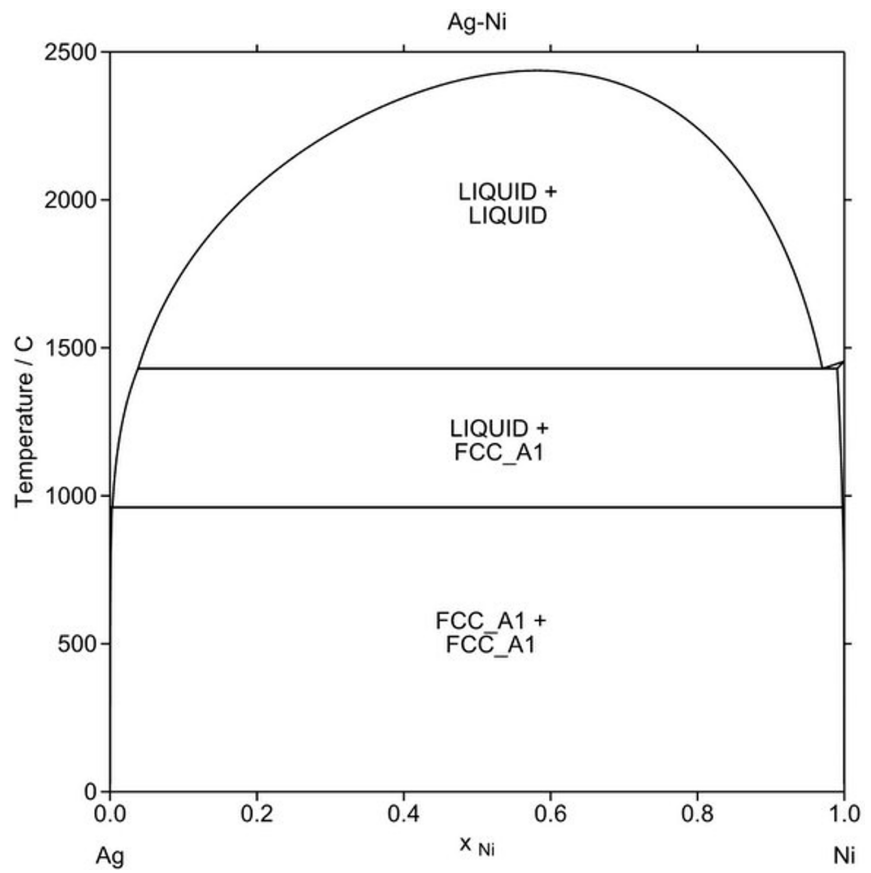

Fig. 1. The phase diagram of Ag-Ni alloy [13]

\section{Methods}

\subsection{Production of AgNi10 composite}

The AgNi10 composite was prepared from the following powders:

- $\quad$ Ag powder with a grain size $<200 \mu \mathrm{m}-$ silver of Ag0 grade (99.99\%),

- $\quad$ Ni powder with a grain size $<5 \mu \mathrm{m}-\operatorname{nickel}(99.9 \%)$.

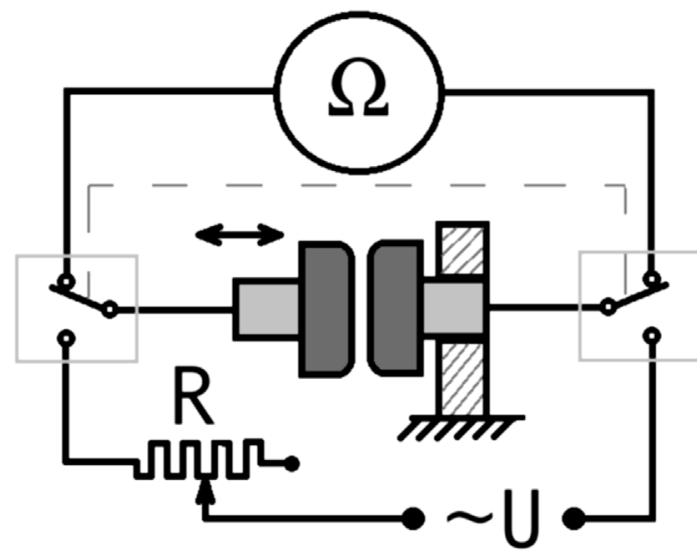

To produce the AgNi10 composite, $90 \%$ Ag powder and $10 \% \mathrm{Ni}$ powder were used. The consolidation of powder was performed by deformation using Cyclic Extrusion Compression Method (CEC). The powder was introduced in the copper chamber with the $10 \mathrm{~mm}$ in diameter and shape well-fitting to the shape of the CEC die.

Optimal consolidation was obtained after $4 \mathrm{CEC}$ cycles with summary deformation $\varphi=1,68$. Next the samples compacted by CEC were Hydrostatically Extruded (HE) to the deformation $\varphi=1,82$. As a result of the HE, the wire with $3 \mathrm{~mm}$ in diameter was obtained. From such produced wires the electrical contacts were produced in the Lucas-Milhaupt Gliwice Sp. z o.o. The procedure of electrical contacts formation was following:

The drawn wire after $\mathrm{HE}$ was subjected to recrystallization annealing at a temperature of $600^{\circ} \mathrm{C}$ for the time of 60 minutes. In the next step, the wire was drawn in a single pass to the target diameter of $\rightarrow 1.90 \mathrm{~mm}$

Rivets were made in a two-stroke horizontal upset forging machine. Then they were degreased in batches in tetrachlorethylene. The ready contacts were annealed in an atmosphere of nitrogen at a temperature of $480^{\circ} \mathrm{C}$ for the time of 60 minutes.

\subsection{Investigations}

Contacts made from the AgNi10 alloy were tested for tribological wear and tear and for changes in electrical properties [14] after a number of operating cycles. The focus was on the problem of contact wear due to arcing (the corrosion caused by electric arc). The parameters of the current used were chosen in such a way as to provoke sparking of contacts, on the one hand, while maintaining, on the other hand, the standard current operating limits proper for the type of material tested and contact geometry. To carry out tests, a special test rig was designed (Fig. 2). Tests were carried out at room temperature $\left(21^{\circ} \mathrm{C}\right)$ with air humidity in the range of $30-40 \%$.

The measuring device was provided with sockets that allowed mounting of contacts without the need for their deformation. The sockets were made of M63 brass, which ensured high electrical conductivity and heat transfer from the operating

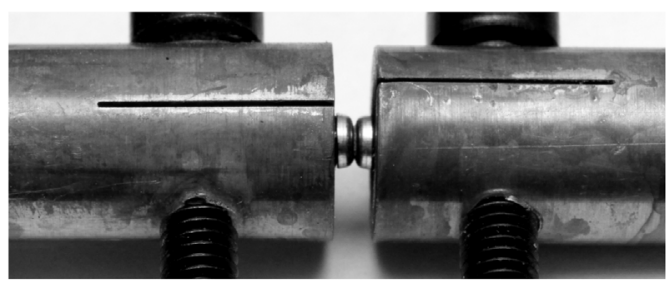

Fig. 2. The scheme of device used to measure the tribological wear of contacts. Visible on the left side is the rig for the assembly of contacts 
contacts. One contact was mounted in a stationary holder fixed fast to the substrate, while other holder was placed on a movable carriage controlled by a high-precision guide. This arrangement allowed maintaining the alignment of assembly and repeatability of the contact operating conditions. The movable contact was actuated by a servomechanism, and the force was transmitted by a spring of the known characteristics. In this way it was possible to preset with high accuracy the short-circuit cycles with exactly defined time and contact downforce. The frequency of $3 \mathrm{~Hz}$ and a $2 \mathrm{~N}$ downforce were applied. Then the alternating current of a 10A average intensity was passed through contacts. Current measurements were made with a clamp meter, keeping the measurement accuracy at a level of $0.1 \mathrm{~A}$.

The contact head diameter was $2.8 \mathrm{~mm}$. To set the precise current value, an adjustable rheostat with Kanthal wire winding was used.

The measurement system was provided with a device to measure changes in contact resistance caused by the wear. For this purpose, an Agilent 34401 meter was used allowing the resistance measurement with an accuracy of $0.001 \mathrm{ohm}$. A control measurement of the resistance was taken after every 200 cycles of the contact operation.

Microhardness was measured on the contact longitudinal section using a PMT-3 microhardness tester and applying a load of $20 \mathrm{~g}$.

Structure was examined with a SEM Hitachi S-3400N microscope

\section{Results and discussion}

Figure 3 shows the longitudinal sections of AgNi10 contacts after 125 thousand, 250 thousand and 500 thousand cycles.

The increasing number of cycles shows a considerable increase in the rate of the tribological wear of contacts, manifested in cavities on the contact surfaces. In contacts after 125 thousand cycles, the degree of surface wear is small and the irregularities do not exceed 54 microns. In samples after 250 thousand cycles, the depth of defects doubles to approx. 104 microns. It should be noted that total height of the contact head remains at the same level of approx. 930 microns. Cavities are visible in the central part of the contact, which is most exposed to the effect of electric arc formed during switching of contacts (Fig. 4). This wear is particularly evident in the sample after 500 thousand cycles shown in Figure $3 \mathrm{c}$ and $4 \mathrm{c}$. A large loss of material in the central part of the contact is visible. The side edges are heavily distorted and show signs of partial surface melting and flowing out of the contact material. Detailed studies of the images allow concluding that the loss of material is proportional to the number of cycles.

The analysis of various phenomena which occur during the short-circuit leads to the conclusion that the observed material losses are due to burning out of contacts by the electric arc produced in the connection shown in Figure 5. The picture was taken at slow shutter speeds and it shows contacts in the two extreme positions - open / close. On the left side (left pin spaced - open position) are visible thread-like electric discharges spread evenly over the entire surface of contact. Each of such discharges causes local partial melting and partial plasma evaporation of the
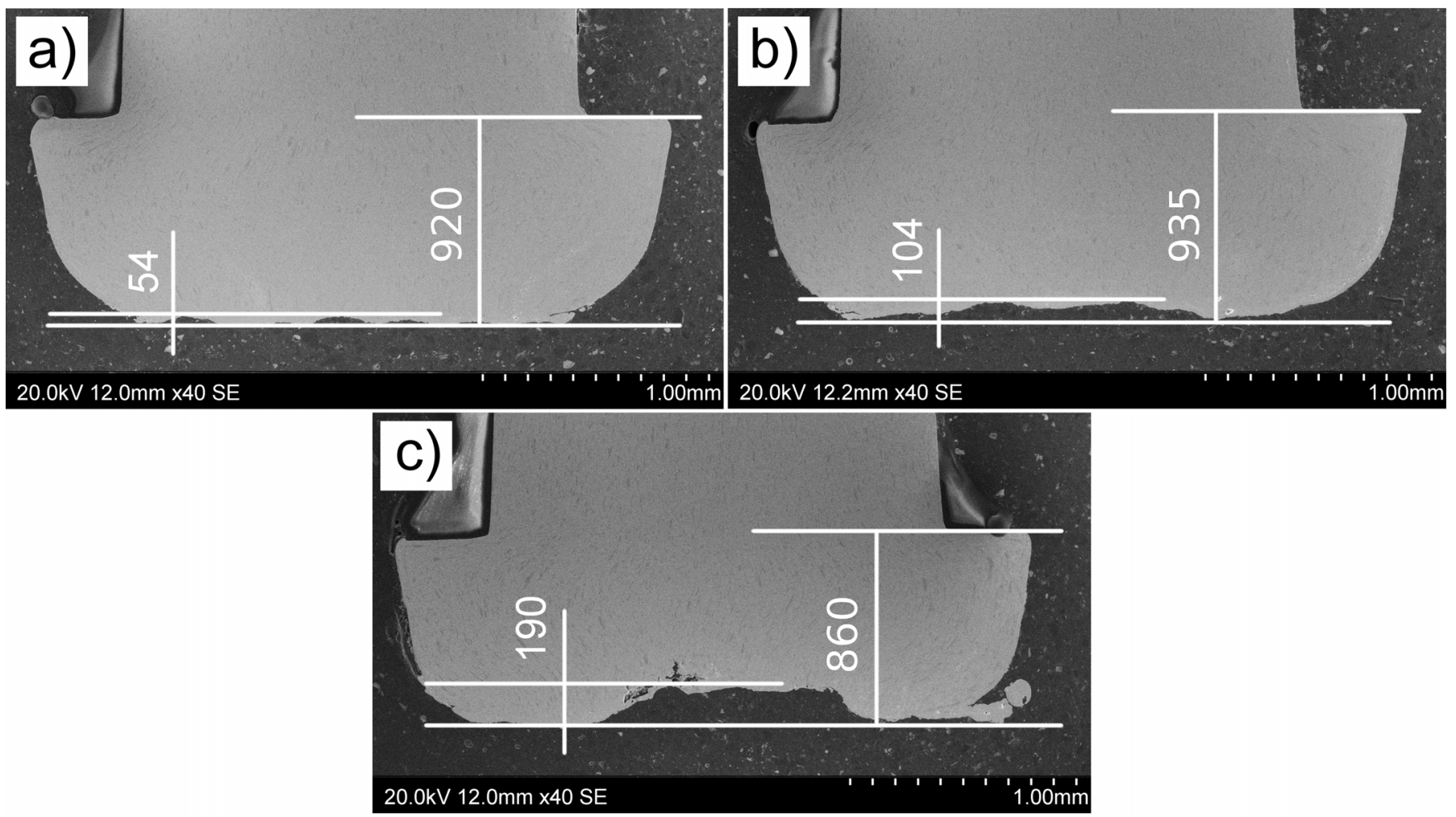

Fig. 3. Microstructure on the longitudinal section of contacts after different number of operating cycles; a) 125 thousand, b) 250 thousand, c) 500 thousand 


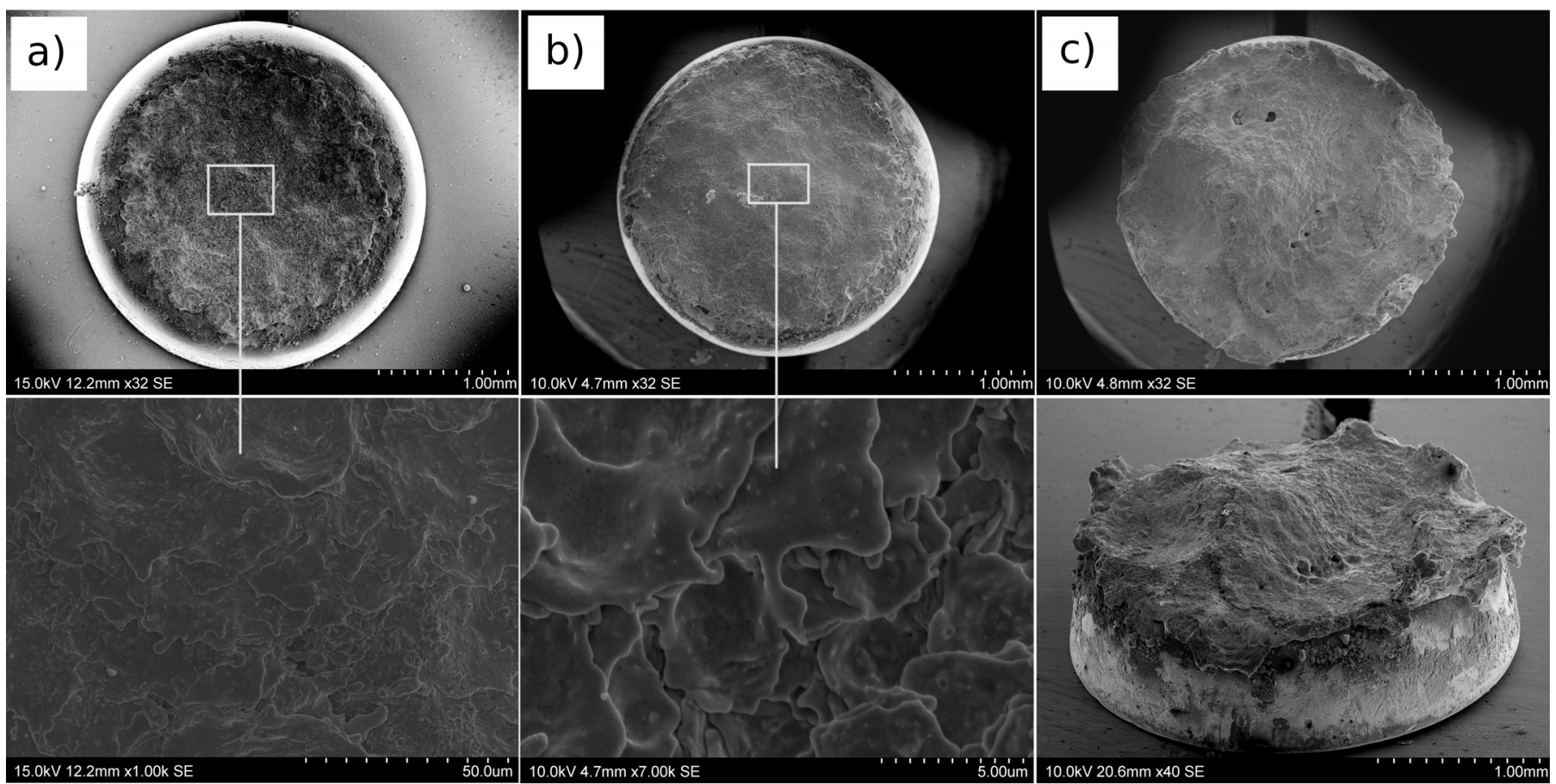

Fig. 4. Contact surface after different number of the operating cycles; a) 125 thousand, b) 250 thousand, c) 500 thousand

material at the arc ends. This thesis has been confirmed by SEM examinations of the contact surface. Figures 6-8 show traces of local partial melting of the contact surface caused by electric arc produced in the connection.

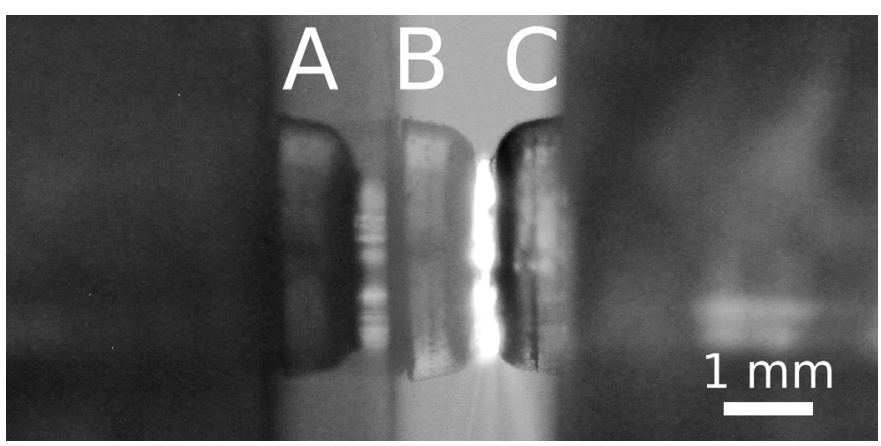

Fig. 5. Arcing of contacts during operation $(\mathrm{I}=10 \mathrm{~A}$ AC, the switching frequency of $3 \mathrm{~Hz}$ ). Photo taken at slow shutter speeds. Visible is the short-circuit (closed) position B-C and the rest (open) position A-C. Visible are also characteristic threads of the electric discharge extending all the way to the rest (open) position of A-C terminals

Figure 6 shows droplets of molten metal formed as a consequence of the local heating of contact surface by electric spark discharges during operation. The size of these artefacts is small and does not significantly affect the size of the active contact surface. The contact surface is uniform over the entire area as shown in Figure 4 a, b. Figure 7 shows fragment of the sample surface after 500 thousand cycles. A much more advanced rate of degradation is observed here compared with the surface of the sample after 250 thousand cycles. The areas of partial melting are much larger and are probably the result of repeated remelting of the same places in the sample. The consequence is high degree

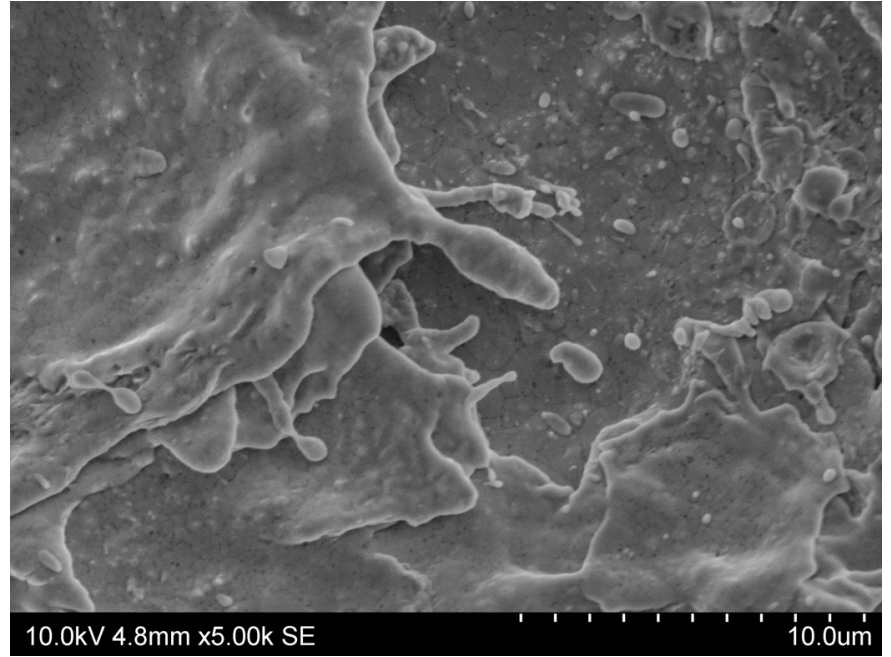

Fig. 6. Drops of metal on the contact surface resulting from local partial melting by electric arc. Sample after 250 thousand cycles

of oxidation of the partially melted areas. On the surface of the sample after 500 thousand cycles (Fig. 9) are visible local micro cracks resulting from the repeated remelting of the material. This effect is accompanied by the formation of thermal stresses and oxides. The result is breaking of the material. Figures 8 and 9 show craters formed on the contact working surface in the place where filamentary electric discharges have been formed. A large loss of material is observed, especially as regards the low-melting phases. The evaporated metal is next condensed on the cold outer surfaces of the contact, forming characteristic structures shown in Figure 10.

The formation of electric arc results in heating of the contact material surface layer with immediate structural consequences. 
Analysis of microstructure on the contact longitudinal section has shown that at the working surface of the contact, a layer of remelted metal was formed with a thickness of 20-50 microns, exhibiting the structure characterized by a high degree of homogenization of the chemical composition.

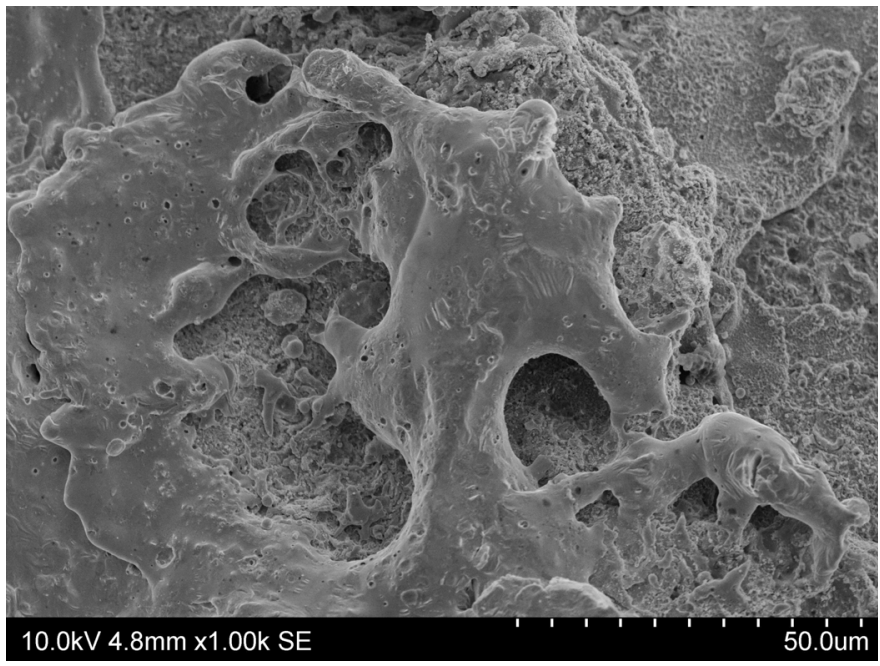

Fig. 7. Partially melted and evaporated material on the contact surface. Sample after 500 thousand cycles

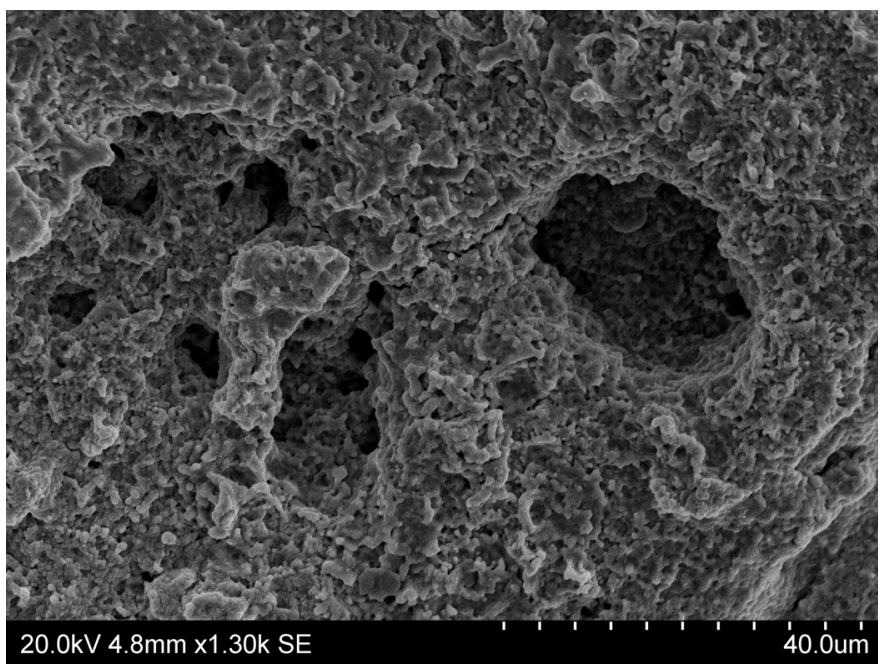

Fig. 8. Craters caused by local evaporation of contact material under the effect of an electric arc. Sample after 500 thousand cycles

The measurements of microhardness (Fig. 12) taken on the contact surface before operation show the hardness value of $67.3 \mathrm{mHV}$ with a standard deviation of $5.7 \%$; on the contact leg cross-section the hardness is $57.1 \mathrm{mHV}$ with a standard deviation of $5.9 \%$.

After a relatively short period of operation (125 thousand cycles), the microhardness of the surface layer remained constant. However, after 250 thousand cycles, a significant increase in microhardness to $80 \mathrm{mHV}$ was observed. This has been confirmed by microstructure examinations. Figure 11 shows microstructure in the selvedge zone of contact. It is characterized by a high degree of homogenization in relation to the structure

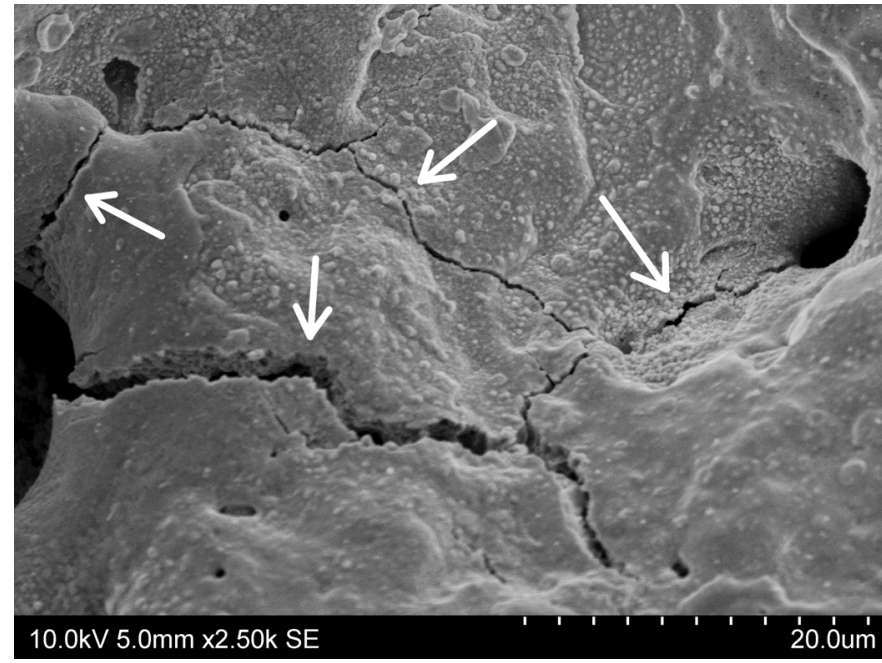

Fig. 9. Cracks visible on the contact surface after 500 thousand cycles caused by repeated remelting and consequent oxidation of the metal

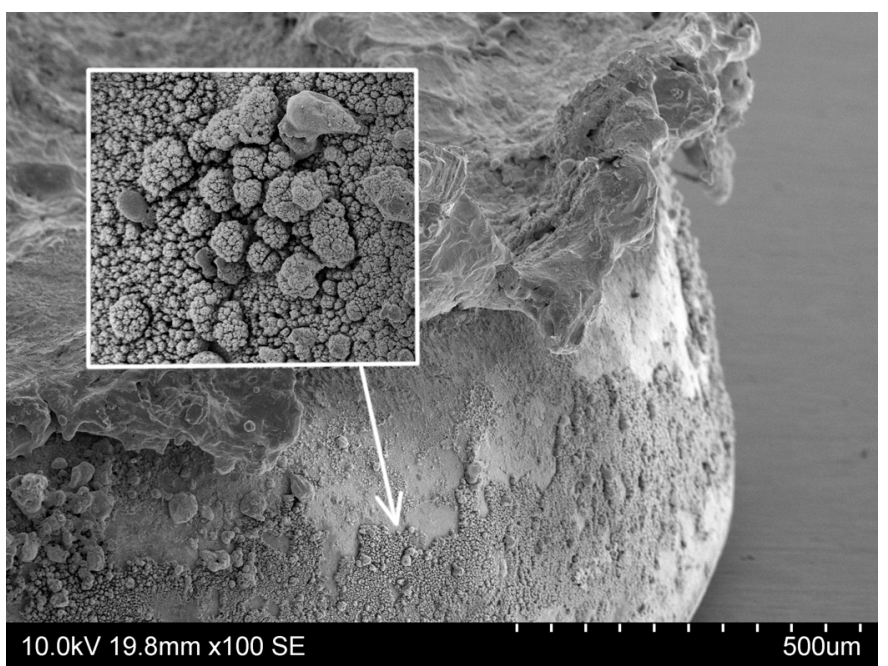

Fig. 10. Typical oxide structure formed as a result of condensation on the cold fragment of contact of the metal vapourised by electric arc. Sample after 500 thousand cycles

in the interior part of the contact. The phases rich in nickel are distributed uniformly over the entire volume of material and cause the observed increase in microhardness. This is an indirect result of the AgNi10 composite manufacturing technology. The material was obtained by powder metallurgy, and therefore the chemical composition in microregions lacks the state of equilibrium. The effect of high temperature during contact operation causes local partial melting, which opens the way to intensive diffusion of components in the liquid/semi-solid phase. This mechanism makes system components strive for the state of thermodynamic equilibrium resulting in fragmentation of the alloy structure. This situation occurs after certain number of cycles at a level of 250 thousand. Too long operation results in repeated remelting, while consequent oxidation of the material has a negative impact on its properties. In the contact structure after 500 thousand cycles, a decrease of microhardness occurs triggered by a strong degradation of the contact surface, as 

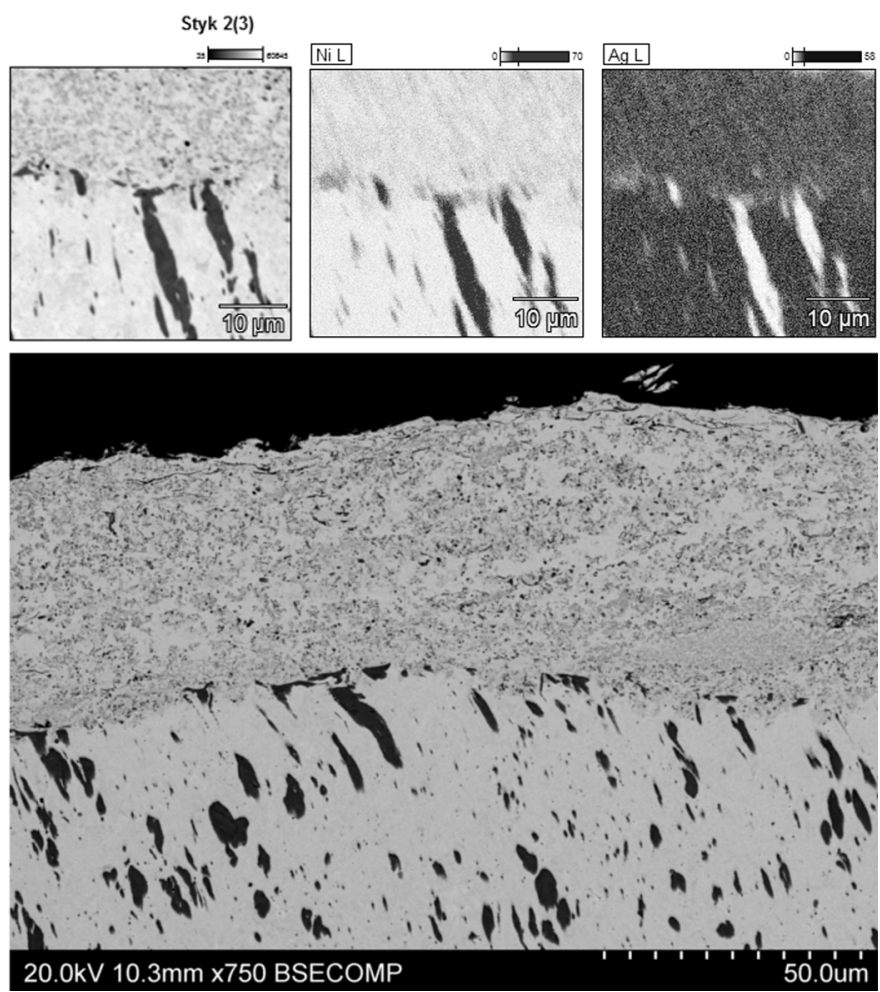

Fig. 11. Selvedge zone of contact after 250 thousand cycles. Visible is strong homogenization of the chemical composition and microstructure fragmentation

shown, among others, in Figure 9. The contact layer is heavily oxidized and after repeated remelting is not as homogeneous as it was after 250 thousand cycles.

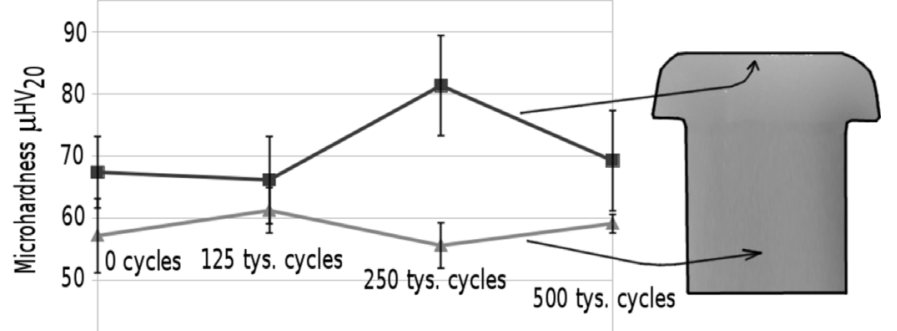

40

Fig. 12. Changes in microhardness observed during operation of contacts made from the AgNi10 composite

Studies of electrical resistance (Fig. 13) conducted in the range of 0 to 250 thousand cycles have revealed that despite the tribological wear of contacts, the resistance remained at a constant level of $0.07 \mathrm{ohm}$ and never dropped below $0.2 \mathrm{ohm}$. The scatter of values visible in Figure 13 took place at each stage of the wear and was caused by irregularities on the contact surface. Despite preservation of the alignment during testing of contacts, due to irregularities on the front planes, the actual contact area was every time somewhat different. This caused the observed fluctuations in resistance. The persistence of the contact resistance values at a stable level in spite of the wear and tear is due to the specific nature of contact operation. Contact surfaces during operation are heated and even partially melted. They are exposed to the effect of downforce, which produces some degree of fit between the two mating parts. Moreover, in a fit of this type, the contact area increases due to the development of an active surface. This, in turn, weakens the resistance of the connection.

In contacts operating for 500 thousand cycles, a strong deformation has occurred on the contact surfaces with direct impact on the contact resistance. The obtained values of electrical resistance varied in the range of 0.1 to $0.6 \mathrm{ohm}$. Thus, the electrical properties suffered an approximately 4-fold deterioration, but even then the values obtained were still at a level allowing correct operation of the contacts.

\section{Summary}

Experiments have shown that the $\mathrm{AgNi} 10$ composite is material suitable for electrical contacts. The operating conditions of contacts during the tests were much more demanding than during normal operation. The problem was primarily the switching frequency and work with high current load. Under these conditions, 500 thousand cycles caused severe damage to the contact area, mainly due to heating and oxidation. However, despite this, the electrical properties of the system remained at a satisfactory level allowing further operation. Hardness of the surface layer of contacts was observed to increase after a certain period of operation. This phenomenon was considered advantageous for the life of contacts, prolonging this life without compromising the electrical properties.

In the examined samples, the degree of wear and tear in the central part of contact was proportional to the number of cycles, while surfaces located on the outer circumference were consumed much more slowly. Considering all these results, it seems doubtful whether the currently used contact geometry is optimum in terms of the tribological wear and tear behaviour.

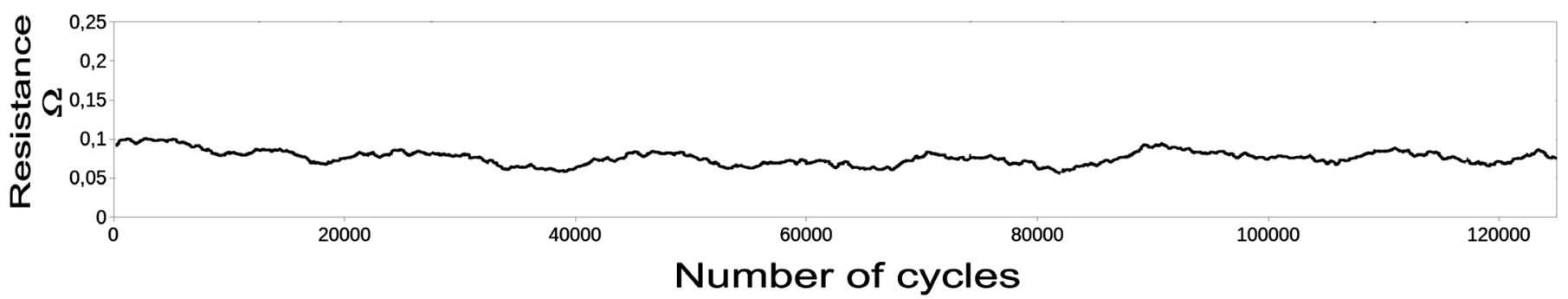

Fig. 13. Changes in electrical resistance of contacts depending on the number of operating cycles. Test made after 250 thousand cycles 


\section{Acknowledgements}

The work is supported by European Program No POIG.01.01.02-00015/09-00.

\section{REFERENCES}

[1] S. Księżarek, M. Woch, D. Kołacz, M. Karpiński, K. Rudnicki, Rudy i Metale Nieżelazne 57 (8), 549-555 (2012).

[2] M.W. Richert, J.A. Smolik, S. Księżarek, Rudy i Metale Nieżelazne 56 (12), 761-765 (2011).

[3] M.W. Richert, J. Richert, M. Książek, A. Hotloś, P. Pałka, M. Perek, Solid State Phenomena 186, 130-134 (2012).

[4] C.P. Wu, D.Q. Yi, C.H. Xu, J. Li, B. Wang, F. Zheng, Corrosion Science 50, 3508-3518 (2008).

[5] G.Boczkal, Materials Letters 134, 162-164 (2014).
[6] D. H. Hea, R. Manory, Wear 249, 626-636 (2001).

[7] G. Boczkal, B. Mikulowski, I. Hunsche, C.G. Oertel, W. Skrotzki, Crystal Research and Technology 43 (2), 135-140, (2008).

[8] T.B. Massalski, Binary Alloy Phase Diagrams, ASM International 1990.

[9] M. Singleton, P. Nash, The Ag-Ni (Silver-Nickel) System, Journal of Phase Equilibria 8 (2), 119-121 (1987).

[10] S. Gacek, Properties of contact materials AgNi20 with dispersion particles of $\mathrm{MgO}$ added, Composites 3, 370-376 (2003).

[11] M. Braunović, V.V. Konchits, N.K. Myshkin, Electrical Contacts: Fundamentals, CRC Press 2007.

[12] G. Boczkal, P. Marecki, M. Perek-Nowak, Archives of Metallurgy and Materials 57, 33-37 (2012).

[13] http://resource.npl.co.uk/mtdata/phdiagrams/agni.htm

[14] D. Stockel, F. Schneider, Silber-Nickel-Fasererbundwerkstoffe fur elektrische Kontakte, Metall 28, 677-683 (1974). 